\title{
RELAÇÕES ENTRE QUALIDADE DA ÁGUA E USO DO SOLO EM GOIÁS: UMA ANÁLISE À ESCALA DA BACIA HIDROGRÁFICA ${ }^{1}$
}

\author{
Barbara Rocha Pinto Bonnet ${ }^{2}$, Laerte Guimarães Ferreira ${ }^{3}$ e Fabio Carneiro Lobo ${ }^{3}$
}

\begin{abstract}
RESUMO - Este trabalho teve por objetivo principal investigar possíveis relações entre qualidade da água e uso do solo em bacias hidrográficas de abastecimento público em Goiás. Nesse sentido, foram compilados dados de 174 captações, operadas pelo Saneamento de Goiás entre janeiro/2002 e dezembro/2004. Médias anuais de seca e de cheia, de turbidez, cor aparente, $\mathrm{pH}$, cloretos e índices de coliforme total e fecal foram relacionadas, por análise de componentes principais, em um índice de qualidade de água (IQA). Com base no mapa de cobertura e uso do solo de Goiás, à escala de 1:250.000, e um mosaico de imagens SRTM (Shuttle Radar Topography Mission), foram delimitadas as bacias de 89 das captações, para as quais foi calculado um Índice Normalizado de Vegetação Remanescente (NRVI). Cor aparente, turbidez, pH, ICT e ICF estiveram aquém dos padrões legalmente requeridos em até $62,43 \%$ das captações analisadas, principalmente nos períodos de cheia, quando os piores valores de IQA são observados. Os resultados indicaram que o IQA utilizado é sensível às variações sazonais e responde ao aporte de sedimentos e matéria orgânica por escoamento superficial. Da mesma forma, esse índice se relaciona, ainda que de forma tênue, às variações regionais nos valores de NRVI. Assim, novos estudos, levando-se em conta outros parâmetros de qualidade da água (como nitrogênio e fósforo) e diferentes escalas da paisagem (ex. zona ripária), são necessários, com vistas a uma melhor determinação dessas relações.
\end{abstract}

Palavras-chave: Uso do solo, qualidade da água e IQA.

\section{WATER QUALITY AND LAND USE RELATIONS IN GOIAS: A WATERSHED SCALE ANALYSIS}

\begin{abstract}
The main goal of this paper was to investigate possible relations between water quality and land use in public water-supplying watersheds in the state of Goias. Thus, data from 174 catchments, operated by Saneamento de Goias were compiled, corresponding to January/2002 - December/2004. Annual, drought and flood season means for turbidity, apparent color, $\mathrm{pH}$, chloride and total and fecal coliform indices (ICT and ICF) were reported and summarized by principal component analysis, into a water quality index (IQA), Based on the land cover map for Goias, at the 1:250,000 scale, and on a SRTM (Shuttle Radar Topography Mission) mosaic, 89 water-supplying watersheds were delimited, for which a normalized remaining vegetation index was calculated. Apparent color, turbidity, $p H, I C T$ and ICF did not achieve the required legal standards in up to $62.43 \%$ of the catchment data analyzed, particularly in the flood season, when the worst IQA values are observed. Our results demonstrate that the IQA utilized is responsible for both the seasonal variations and apportion of sediments and organic matter, via superficial run-off. Likewise, this index is also slightly related to the regional NRVI variations. In order to better determine these relations, further studies are needed, taking into account other water quality parameters (e.g. nitrogen and phosphorous) and different landscape scales (e.g. riparian zone)..
\end{abstract}

Keywords: Land use, water quality and IQA.

\footnotetext{
${ }^{1}$ Recebido em 11.12.2006 e aceito para publicação em 20.02.2008.

${ }^{2}$ Programa de Doutorado em Ciências Ambientais da Universidade Federal de Goiás UFG/CIAMB, Campus II Samambaia, Caixa Postal 131, CEP 74001-970,Goiânia, GO. E-mail: <brpb@uol.com.br>.

${ }^{3}$ Laboratório de Processamento de Imagens e Geoprocessamento da UFG/IESA/LAPIG. E-mail: <laerte@ pesquisador.cnpq.br>.
} 


\section{INTRODUÇÃO}

Nas últimas décadas, Goiás experimentou intensa expansão de suas fronteiras agropecuárias. Entre 1980 e 2004, o Estado foi desmatado a uma taxa média efetiva de $1,14 \%$ ao ano (ANTUNES, 2004). Com isso, as formações florestais nativas foram reduzidas a cerca de 11.590.000 hectares, ou 34\% do Estado, concentrados principalmente no Nordeste goiano (SANO et al., 2006). Esse ritmo de conversão de terras se reflete em pressões sobre os demais recursos ambientais, inclusive os hídricos.

As relações entre uso do solo e as águas estão claramente demonstradas, sendo que a conversão de áreas florestadas, principalmente para o uso agrícola ou urbano, tem sido associada à diminuição da sua qualidade (FREITAS, 2000; TUCCI, 2000; OMETO et al., 2000; GERGEL et al., 2002; SANTOS, 2004; SNYDER et al., 2005). Em grandes extensões territoriais, o conhecimento de parâmetros que relacionem as condições da cobertura vegetal com a qualidade desejável das águas, conforme seu uso preponderante, pode embasar instrumentos de planejamento e padrões de uso do solo (RIPA et al., 2006).

Em Goiás, uma das bases de dados de qualidade das águas superficiais de maior abrangência espacial é a de monitoramento de mananciais de abastecimento público operados pela Saneamento de Goiás S/A, Saneago. Entre 2002 e 2004, seis variáveis foram monitoradas, mensal e regularmente, em 174 captações da empresa: turbidez, cor aparente, $\mathrm{pH}$, cloretos, índices de coliforme total (ICT) e fecal (ICF). Elas são recomendadas para investigação de qualidade de águas de abastecimento superficiais (OMS, 1995; SPERLING, 1996; HERLIHY et al., 1998 citado por OMETO et al., $2000^{4}$ ), embora outras, como sabor e odor, temperatura, alcalinidade e acidez, ferro, manganês e nitrogênio, também o sejam (SPERLING, 1996).

Não há um indicador de qualidade de água único e padronizável para qualquer sistema hídrico. Uma forma de avaliar objetivamente essas variações é a combinação de parâmetros de diferentes dimensões, em índices que os reflitam conjuntamente em uma distribuição amostral no espaço e no tempo (TOLEDO e NICOLELLA, 2002). Trata-se dos índices de qualidade da água, IQAs, que vêm sendo largamente usados em monitoramento há algum tempo (DINIUS, 1987; CUDE, 2001).

Uma instituição pioneira no Brasil no uso de IQAs foi a Companhia de Tecnologia de Saneamento Ambiental, CETESB (CONTE et al., 2000), que utilizou de 1975 a 2001 um IQA desenvolvido a partir de estudos da National Sanitation Foundation, em 1970, nos Estados Unidos (CETESB, 2006). Desde 2002, a CETESB utiliza três índices específicos aos usos de cada recurso hídrico: abastecimento público (IAP), proteção da vida aquática (IVA) e balneabilidade.

Já o Oregon Water Quality Index, OWQI, integra temperatura, $\mathrm{OD}, \mathrm{DBO}, \mathrm{pH}$, amônia e nitratos, fósforo total, sólidos totais e ICF. Desenvolvido e atualizado desde a década de 1970, o OWQI é voltado ao uso geral e recreacional das águas superficiais (CUDE, 2001). Diversos outros índices foram desenvolvidos com base em características físico-químicas da água ou a partir de indicadores biológicos, cabendo ajustes nos pesos e parâmetros para adequação à realidade regional. Usualmente, estes IQAs são baseados em poucas variáveis (GERGEL et al., 2002), cuja definição deve refletir as alterações potenciais ou efetivas, naturais ou antrópicas que ela sofre (TOLEDO e NICOLELLA, 2002).

Ao serem relacionadas a indicadores de qualidade da água, diversas métricas de paisagem e uso do solo podem refletir a intensidade das alterações antrópicas, principalmente no âmbito da bacia hidrográfica (GERGEL et al., 2002; HOULAHAN e FINDLAY, 2004). A própria legislação florestal brasileira (Lei 4771/1965 e suas atualizações) expõe a conveniência pela gestão territorial por bacias hidrográficas, instituídas como unidades de planejamento ambiental no Brasil pela Política Nacional de Recursos Hídricos (Lei 9433/1997).

Neste sentido, Ometo et al. (2000) desenvolveram um índice de uso do solo (Land Use Index, $L U I$ ) formado pela soma, ponderada por valores arbitrários, das áreas porcentuais ocupadas pela forma de uso do solo mais

\footnotetext{
${ }^{4}$ HERLIHY, A. T.; STODDARD, J. L.; JOHNSON, C. B. The relationship between stream chemistry and watershed land cover data in the Mid-Atlantic region, U.S. Water, Air, and Soil Pollution, n.105, p.377-386. 1998. Citado por OMETO, J. P. H. B.et al. Effects of land use on water chemistry and macroinvertebrates in two streams of the Piracicaba river basin, south-east Brazil. Freshwater Biology, v.44, p.327-337, 2000.
}

R. Árvore, Viçosa-MG, v.32, n.2, p.311-322, 2008 
importante em cada sub-bacia componente de uma bacia de drenagem de maior porte, à qual se relacionaram variáveis de sólidos suspensos totais e nitratos. Um índice semelhante foi proposto por Fidalgo et al. (2003). Outras métricas são baseadas na diversidade das formas de uso na paisagem e aquelas baseadas no percentual de cobertura vegetal (MEADOR e GOLDSTEIN, 2003).

Bonnet et al. (2006) propuseram um índice normalizado de vegetação remanescente (Normalized Remaining Vegetation Index, NRVI), diretamente proporcional ao porcentual de cobertura vegetal remanescente de determinada bacia hidrográfica, variando de $-1 \mathrm{a}+1$. Um NRVI igual $\mathrm{a}+1$ indica uma bacia totalmente ocupada por cobertura vegetal nativa, enquanto um NRVI igual a - 1 indica que toda a bacia se encontra sob uso antrópico. O NRVI é adimensional e atenua a importância da área entre as bacias, o que facilita a verificação de correlações do uso do solo com variáveis de outros índices adimensionais, como o IQA.

A legislação florestal brasileira estabelece uma área mínima de cobertura vegetal nativa em cada bacia, no Estado de Goiás, de $20 \%$ de Reserva Legal (o porcentual é variável entre os Estados e regiões fitoecológicas) e de áreas de preservação permanente, associadas, entre outras, às margens de cursos d'água, ao entorno de nascentes, veredas, lagos, lagoas ou reservatórios, como também a topos de morros, montes, montanhas e serras, áreas declivosas e linhas de ruptura de relevo.

Das áreas de preservação permanente, Bonnet et al. (2006) estimaram que aquelas associadas a ambientes ripários deveriam ocupar em média $10,9 \%$ da área estadual, tomando-se como referência um buffer com largura média de $100 \mathrm{~m}$ em torno de cada margem de cursos d'água detectáveis à escala 1:250.000. Cumpre destacar que esta média é uma mera referência, tendo em vista que a largura da faixa marginal aos corpos d'água e a área qualificada como de preservação permanente em cada propriedade são variáveis. Considerando-se a proporcionalidade entre o NRVI e o porcentual de remanescentes, um NRVI igual a 0,382 equivale à presença de $30,9 \%$ de remanescentes de cobertura vegetal em cada bacia, correspondentes à área mínima legalmente requerida.

As duas escalas extremas de mensuração de indicadores de paisagem são a totalidade da bacia hidrográfica e a zona ripária (RIBEIRO et al., 2005). Ambas já se mostraram úteis como preditoras de variáveis físicas e químicas (GERGEL et al., 2002). Ao avaliar 503 bacias nos Estados Unidos, Baker et al. (2006) constataram relações distintas entre o uso do solo na bacia inteira e na zona ripária em diferentes regiões fisiográficas. Já para Meador e Goldstein (2003) aspectos como geologia e uso do solo podem ser mais importantes que as zonas ripárias na restauração de ambientes lóticos. Também se constata facilmente o efeito da vegetação e da paisagem na zona ripária sobre a qualidade das águas (MIRANDA JÚNIOR, 2002; GERGEL et al., 2002; SNYDER et al., 2005). Meador e Goldstein (2003) associaram indicadores métricos desfavoráveis na zona ripária à contaminação difusa da água.

No sentido de contribuir para esta discussão, este trabalho teve como principal objetivo investigar relações entre a qualidade da água e o uso do solo em bacias hidrográficas de mananciais superficiais de abastecimento público em Goiás. Especificamente, buscou sintetizar uma base de dados de qualidade da água a partir dos parâmetros disponíveis e integrá-los em IQAs anual e sazonal, bem como espacializar essas bacias de captação e aplicar o NRVI para a totalidade de suas áreas. Em seguida, foram avaliadas as relações entre os IQAs produzidos e a proporção de remanescentes, em função dos respectivos valores de NRVI para as bacias de mananciais utilizadas no Estado.

\section{MATERIAL E MÉTODOS}

\subsection{Aquisição de dados}

Dados analíticos e cartográficos foram adquiridos de diferentes fontes para este trabalho. na Saneago foram obtidos resultados de análises de parâmetros de qualidade da água superficial para 174 pontos de captação, operados pela empresa entre janeiro de 2002 e dezembro de 2004. Os métodos analíticos utilizados pela Saneago estão de acordo com APHA (1998). Embora se dispusesse de uma variedade de 27 parâmetros de qualidade coletados mensal ou eventualmente entre os pontos de captação, apenas seis deles tiveram regularidade de amostragem em todos os pontos ao longo do período: turbidez, cor aparente, $\mathrm{pH}$, cloretos, ICT e ICF. Esses parâmetros foram utilizados para o ordenamento de uma base de dados.

Os dados cartográficos incluíram o mapa de uso do solo em Goiás, elaborado no âmbito do projeto

R. Árvore, Viçosa-MG, v.32, n.2, p.311-322, 2008 
Identificação de Áreas Prioritárias para Conservação da Biodiversidade no Estado de Goiás a partir de imagens de satélite Landsat 7 ETM+ de 2002 e 2003, na escala original de 1:250.000 (SANO et al., 2006) e um mosaico de imagens SRTM (Shuttle Radar Topography Mission), compreendendo 72 imagens, geradas em 2000 e distribuídas pelo United States National Geological Survey, com tile de 1 grau geográfico e resolução espacial de 91,63 m.

Houve preocupação em utilizar um conjunto de dados que refletisse a variabilidade temporal dos parâmetros de qualidade da água - pela adoção de uma série histórica de três anos consecutivos - como também uma distribuição espacial que abarcasse as diversas paisagens do Estado. As Figuras 1 e 2 ilustram a disposição dos 174 pontos de captação sobre mapas de divisão municipal e de bacias hidrográficas com área mínima de 200.000 hectares, produzidas para o Estado por Bonnet et al. (2006). Todos os pontos de captação foram considerados para a estimativa de um IQA. No entanto, bacias de captação com área inferior a 500 ha foram desconsideradas na determinação do NRVI, o que resultou em uma coleção de 89 pontos, destacados nas Figuras 1 e 2 .

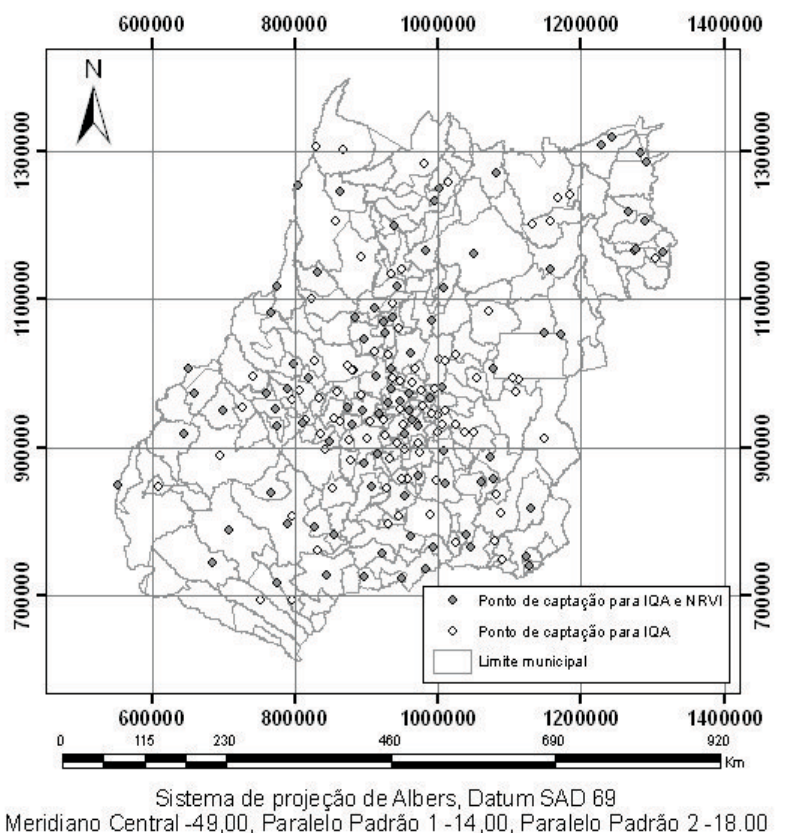

Figura 1 - Distribuição espacial dos pontos de captação em relação aos municípios de Goiás.

Figure 1 -Spatial distribution of catchment area points in the municipalities of Goias.

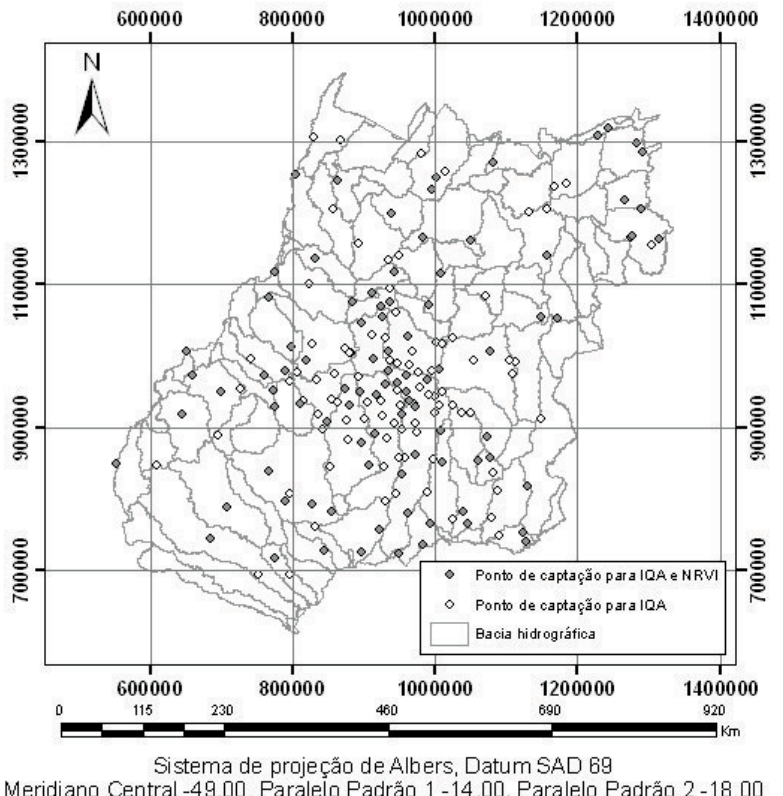

Figura 2 - Distribuição espacial dos pontos de captação em relação às bacias hidrográficas com área mínima de 200.000 ha, em Goiás.

Figure 2 -Spatial distribution of catchment area points in watersheds with minimum area of 200,000 ha in Goias.

\subsection{Processamento e análise de dados}

Os dados de qualidade da água foram revisados para a retirada de inconsistências do conjunto. Valores de ICT menores que os de ICF na mesma análise e extremos de diluição de amostras, com resultados maiores que 1.000.000 NMP/100 mL foram ignorados. Dados de cor aparente ou turbidez maiores que $1.000 \mathrm{uH}$ ou 1.000 NTU, respectivamente, sem resultados proporcionais no restante dos dados, ou valores superiores a 5.000 uH ou 5.000 NTU em coleções com resultados proporcionalmente altos, foram retirados.

Dos parâmetros, foram obtidas médias anuais por ponto, considerando-se todos os meses do período, bem como médias de seca e de cheia, a partir dos dados dos quadrimestres mais secos e mais úmidos no período, respectivamente. Todas as médias foram transformadas por logaritmo natural. Ocorre regionalmente um retardo de cerca de 30 dias entre os ritmos pluviométricos e fluviométricos, pelo quê o quadrimestre de seca foi considerado entre junho e setembro e o de cheia, entre janeiro e abril. 
As médias dos seis parâmetros selecionados, considerando-se os 174 pontos, foram submetidas a uma análise de componentes principais para as médias anuais, de seca e de cheia. Da análise, foram produzidas matrizes de correlação entre os parâmetros, auto-valores relativos à variância total dos dados distribuída em seis componentes, bem como um conjunto auto-vetores proporcionais à contribuição de cada parâmetro nos respectivos componentes. Assim, foi obtido um IQA associado a cada componente (equação 1):

$$
\mathrm{IQA}_{\mathrm{n}}=\Sigma\left(\mathrm{p}_{1} \cdot \mathrm{c}_{\mathrm{n}}: \mathrm{p}_{6} \cdot \mathrm{c}_{\mathrm{n}}\right)
$$

em que $\mathrm{p}=$ valor de cada um dos seis parâmetros e $\mathrm{c}=$ coeficiente (peso) do auto-vetor $\mathrm{n}$.

A partir dos seis IQAs (equação 1) foi também produzido um IQA ponderado, conforme o respectivo porcentual de explicação da variância total em cada componente (equação 2):

$$
\mathrm{IQA}_{\mathrm{p}}=\Sigma\left(\mathrm{IQA}_{1} \cdot \%_{1}: \mathrm{IQA}_{6} \cdot \%_{6}\right)
$$

em que IQA $\mathrm{I}_{1: 6}=$ valor de IQA para cada componente e \% = porcentual de explicação da variância total dos dados em cada auto-valor.

Os dados foram obtidos para médias anuais, de seca e de cheia. Também foi inferido um índice de contraste sazonal entre os IQAs de seca e de cheia para cada ponto de captação (equação 3 ):

Índice de contraste sazonal $=\left(\mathrm{IQA}_{1}\right.$ cheia $-\mathrm{IQA}_{1}$ seca)/IQA 1 cheia

Em relação às bacias hidrográficas geradas a partir das imagens SRTM, inicialmente procedeu-se à correção de gaps e geração de um mosaico, através do software ENVI 4.0. O mosaico foi processado com o software ArcGIS, acrescido das funcionalidades ArcHydro (GISWR, 2006), com o qual foi produzido um MDT (Modelo Digital do Terreno) hidrologicamente coerente, através da função fill sinks. Em seguida foram gerados os limites das bacias hidrográficas, tendo como exutórios os 174 pontos de captação. Conforme já mencionado, do conjunto de bacias espacializadas foram retiradas aquelas com área inferior a 500 hectares, haja vista limitações de escala. Assim, ao todo, foram analisadas 89 bacias.

Para o cálculo do NRVI, as formas de uso e cobertura da terra, mapeadas à escala de semi-detalhe, foram reunidas em duas categorias: "uso", compreendendo as classes cultura anual, cultura em pivô central e pastagem, e "remanescente de cobertura vegetal nativa", compreendendo as classes floresta estacional decidual submontana e montana; floresta estacional semidecidual aluvial, de terras baixas, submontana e montana; formações pioneiras fluviais elou lacustres; savana arborizada, florestada, gramíneo lenhosa $\mathrm{e}$ savana parque. As formas água, reflorestamentos, sítios urbanos, solo exposto e nuvens foram desconsideradas. Tendo por base a área e perímetro de cada bacia de captação, bem como de cada polígono de uso e remanescente dentro das bacias, foi calculado o NRVI (equação 4):

$$
\text { NRVI } \frac{\text { área }{ }_{\text {remanescente }}-\text { área }_{\text {uso }}}{\text { área }{ }_{\text {remanescente }}+\text { área }}
$$

\section{RESULTADOS E DISCUSSÃO}

\subsection{Parâmetros de qualidade da água e suas correlações}

Os parâmetros utilizados no IQA para médias anuais, de seca e de cheia nos pontos de captação e períodos avaliados são sumarizados no Quadro 1. Em relação aos padrões requeridos pelas Resoluções CONAMA 001/86 e 357/055 para águas de Classe 2, a única variável totalmente em conformidade foram cloretos, seguida pelo $\mathrm{pH}$ e pela turbidez, com pequeno porcentual de valores afastados do padrão.

No entanto, resultados não-conformes para as variáveis ICT e ICF chegam a 62,43\% (ICF na cheia), nunca sendo inferiores a 28,74\% (ICT na seca). À exceção do $\mathrm{pH}$, em face de seu range, o coeficiente de variação dos parâmetros é bastante alto, tanto na média anual quanto nas sazonais. Isso se justifica pela própria natureza

\footnotetext{
${ }^{5}$ Os dados em avaliação datam de 2002 a 2004, quando ainda vigorava a Resolução CONAMA 020/86, revogada em favor da Resolução CONAMA 357/05, que ensejou a adoção de coliformes termotolerantes como indicadores biológicos de qualidade da água, em detrimento do ICT e do ICF. Os padrões de turbidez, pH e cloretos para águas superficiais de Classe 2 de uso preponderante (referência para águas não classificadas especificamente, como ocorre em Goiás) não foram alterados, tendo se mantido em 100 NTU, 6 a 9 e $250 \mathrm{mg} / \mathrm{L}$, respectivamente. O padrão de cor se manteve igual (75 uH) mas foi definido como de cor verdadeira, determinada após centrifugação. Os padrões para ICT e ICF foram alterados de 5000 NMP/100 $\mathrm{mL}$ e $1.000 \mathrm{NMP} / 1.000 \mathrm{~mL}$, respectivamente, para $1.000 \mathrm{NMP} / 100 \mathrm{~mL}$ de coliformes termotolerantes.
} 
dos dados e pelas múltiplas influências que podem sofrer (TOLEDO e NICOLELLA, 2002). Não obstante, picos de turbidez, cor e ICF são essencialmente associados à cheia.

Tanto as médias anuais quanto as sazonais evidenciam maiores correlações entre ICT x ICF e cor aparente x turbidez. As correlações ICT $\mathrm{x}$ pH e ICF x pH se destacam na cheia e na seca, embora sejam bem menores nas médias anuais. Para os parâmetros de cheia e médias anuais, destacamse correlações ICT x cor aparente e ICF x cor aparente, que diminuem na média de seca. Durante a cheia aumentam também as correlações ICT $\mathrm{x}$ turbidez e ICF x turbidez e entre $\mathrm{pH}$ x cor e $\mathrm{pH}$ x turbidez. A Figura 3 sintetiza essas correlações.

Enquanto a Resolução CONAMA 001/86 propunha implicitamente uma proporção de 1:5 entre ICF e ICT, os dados analisados neste trabalho indicam uma proporção de aproximadamente $1: 3$ na média anual, $1: 7,5$ na seca e quase $1: 2$ na cheia. Da mesma forma, as correlações ICF $x$ ICT foram as mais altas constatadas nos IQA anual e sazonal. A grande dispersão do ICT, em face da diversidade de habitats afeitos aos coliformes, o limita como preditor da ocorrência de patógenos. Por sua vez, o ICF tem forte contribuição de E. coli em sua composição - única espécie do grupo dos coliformes termotolerantes cujo habitat exclusivo é o trato intestinal humano e o de animais homeotérmicos, onde ocorre com grande densidade pelo que é indicador de tal contaminação (SPERLING, 1996; OMS, 1995).

Em relação à cor aparente, que é em parte atribuível à turbidez, é esperada correlação entre essas variáveis. A turbidez pode estar relacionada ao aporte de efluentes, à erosão e a patógenos, que podem se adsorver e proliferar entre os sólidos em suspensão que a determinam (OMS, 1995). Essas duas possibilidades devem ser consideradas nas bacias estudadas, tendo em vista as correlações mútuas entre ICT, ICF, turbidez e cor aparente, especialmente nas médias de cheia.

As relações entre pH e as variáveis ICT, ICF, cor aparente e turbidez são menos típicas. Outros autores constataram correlações de $\mathrm{pH}$ com variáveis que não puderam ser incluídas neste IQA, como temperatura (CARVALHO etal., 2000), OD (TOLEDO e NICOLELLA, 2002) e DBO (PIMENTEL, 2003). Tendo em vista que foram considerados pontos amostrais em todo o território goiano, não se espera que as alterações de $\mathrm{pH}$ estejam associadas a unidades geológicas específicas ou à absorção de gases da atmosfera (SPERLING, 1996). De fato, as variações de $\mathrm{pH}$ parecem estar mais associadas às variáveis afins à matéria orgânica em sedimentos, como ICT e ICF, cor aparente e turbidez, haja vista as correlações observadas e o forte caráter sazonal que estas apresentam.

Quadro 1 - Parâmetros de qualidade da água analisados: estatística descritiva dos dados analisados e padrões das Resoluções CONAMA 020/86 e 357/05

Table 1 - Water quality parameters analyzed: descriptive statistics of the data analyzed and standards of the Resolutions CONAMA 020/86 and 357/05

\begin{tabular}{|c|c|c|c|c|c|c|c|}
\hline \multirow{2}{*}{\multicolumn{2}{|c|}{ Parâmetro }} & Turbidez & Cor & $\mathrm{pH}$ & Cloretos & $\mathrm{ICT}$ & \\
\hline & ade & NTU & $\mathrm{uH}$ & & $\mathrm{mg} / \mathrm{L}$ & $\mathrm{NMP} / 100 \mathrm{~mL}$ & $\mathrm{NMP} / 100 \mathrm{~mL}$ \\
\hline \multicolumn{2}{|c|}{ Padrão CONAMA 020/86* } & 100 & 75 & 6 a 9 & 250 & 5.000 & 1.000 \\
\hline \multicolumn{2}{|c|}{ Padrão CONAMA $357 / 05 *$} & 100 & 75 & 6 a 9 & 250 & $1000 \mathrm{NMP} / 100 \mathrm{~mL}$ & \\
\hline \multirow{5}{*}{$\frac{\overparen{\pi}}{\Xi}$} & Valor mínimo & 0,23 & 0,00 & 5,6 & 0,26 & 6,00 & 3,00 \\
\hline & Valor máximo & 190,35 & 438,08 & 7,7 & 30,19 & $105.836,57$ & $32.712,18$ \\
\hline & Média & 28,98 & 80,21 & 7,0 & 8,78 & $9.034,92$ & $4.080,69$ \\
\hline & Coeficiente de variação & 1,06 & 1,00 & 0,06 & 0,81 & 1,60 & 1,47 \\
\hline & Não conformidade $\%$ & 5,52 & 37,57 & 2,76 & 0,00 & 38,67 & 60,22 \\
\hline \multirow{5}{*}{$\begin{array}{l}\tilde{J} \\
\mathscr{N}\end{array}$} & Valor mínimo & 0,00 & 0,00 & 5,5 & 0,00 & 3,00 & 3,00 \\
\hline & Valor máximo & 49,95 & 184,50 & 7,9 & 37,68 & $219.246,67$ & $29.192,09$ \\
\hline & Média & 8,72 & 33,15 & 7,0 & 8,73 & $8.425,56$ & $2.512,12$ \\
\hline & Coeficiente de variação & 0,83 & 1,01 & 0,07 & 0,89 & 2,84 & 1,89 \\
\hline & Não conformidade $\%$ & 0,00 & 9,71 & 4,00 & 0,00 & 28,74 & 45,40 \\
\hline \multirow{5}{*}{$\frac{\frac{\pi}{v}}{\frac{d}{U}}$} & Valor mínimo & 0,30 & 4,56 & 5,4 & 0,36 & 50,00 & 3,00 \\
\hline & Valor máximo & 419,86 & 865,15 & 8,9 & 21,33 & $119.475,00$ & $64.275,00$ \\
\hline & Média & 54,57 & 138,29 & 6,9 & 8,11 & $9.906,68$ & $5.230,99$ \\
\hline & Coeficiente de variação & 1,16 & 1,02 & 0,07 & 0.81 & 1,47 & 1,81 \\
\hline & Não conformidade $\%$ & 16,76 & 60,12 & 4,05 & 0,00 & 45,09 & 62,43 \\
\hline
\end{tabular}

* Valores para águas de classe 2 de uso preponderante em ambas as resoluções.

R. Árvore, Viçosa-MG, v.32, n.2, p.311-322, 2008 


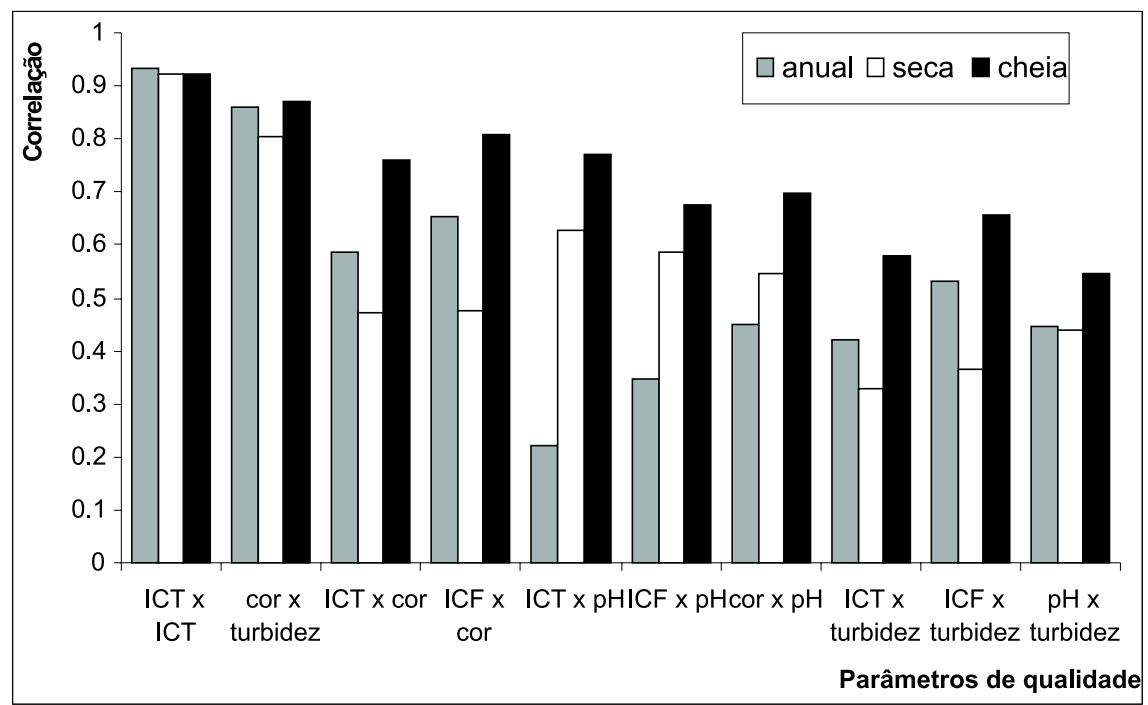

Figura 3 - Correlação entre os parâmetros de qualidade de água analisados.

Figure 3 -Correlation between the analyzed water quality parameters.

Embora poucos, e ainda que não tenham sido obtidas correlações consistentes para cloretos, os parâmetros utilizados no IQA estão associados, em alguma instância, ao aporte aos cursos d'água de sedimentos com matéria orgânica adsorvida, associados ao uso agropecuário da terra. Essas correlações se maximizam em época de cheia, sugerindo que a contribuição do escoamento superficial seja determinante para as variações de qualidade da água em mananciais de abastecimento públicos superficiais de Goiás.

\subsection{IQA anual e sazonal}

A análise de componentes principais apontou que o IQA ${ }_{1}$, obtido através da ponderação dos parâmetros em função dos coeficientes do auto-vetor 1, explica, respectivamente, $54,16 \%, 54,02 \%$ e $66,02 \%$ da variância total das médias anual, de seca e de cheia (Figura 4). São valores compatíveis com aqueles obtidos por Toledo e Nicolella (2002) para uma bacia hidrográfica sob múltiplos usos no interior paulista, que formularam um IQA a partir da primeira componente principal, detentora de $47 \%$ da variância total dos dados. Comparativamente ao IQA, ponderado segundo os respectivos autovalores, a representatividade do IQA é também corroborada pelos elevados $\mathrm{r}^{2}$ entre os dois índices: 0,98, 0,96 e 0,99 para as médias anual, de seca e cheia, respectivamente. Em face disso, o IQA foi adotado neste trabalho.

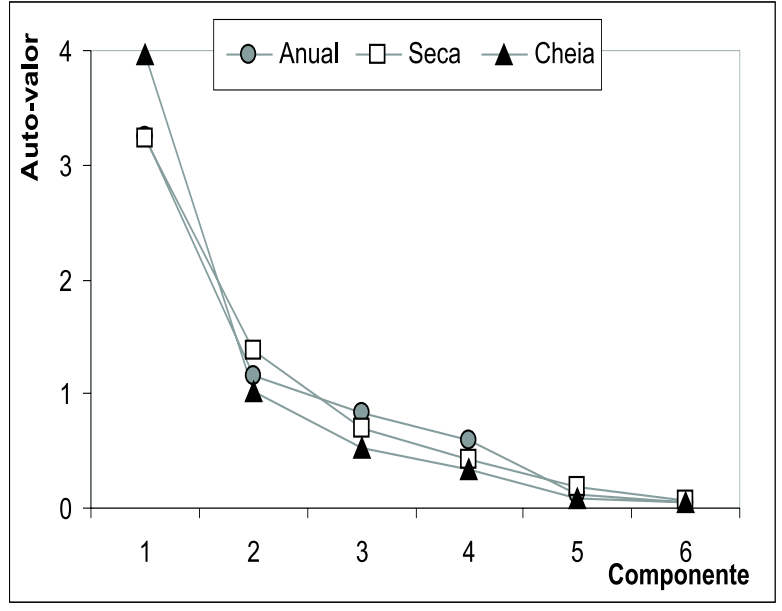

Figura 4 - Autovalores de cada componente analisado em relação ao conjunto de dados anual, de seca e cheia.

Figure 4-Eigen-values of each component analyzed according to annual, drought and flood datasets.

Os coeficientes (pesos) do autovetor 1 para cada parâmetro de IQA 1 anual, de seca e de cheia são mostrados na Figura 5. Os parâmetros com maiores pesos são cor aparente, ICF e turbidez para médias anuais, ICT, ICF e cor aparente para médias de seca e cor aparente, ICT e ICF para médias de cheia, nesta ordem. É interessante observar que esses parâmetros correspondem àqueles com os maiores valores de correlação (Figuras 3 e 5).

R. Árvore, Viçosa-MG, v.32, n.2, p.311-322, 2008 


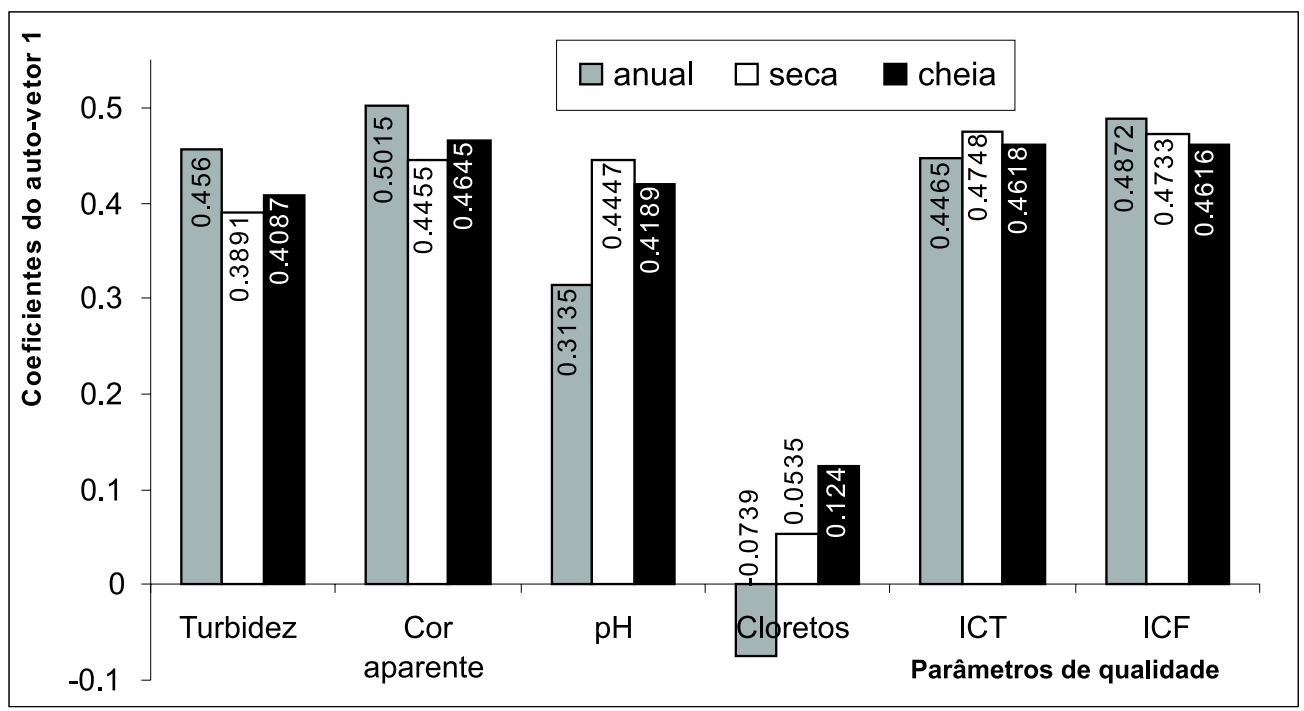

Figura 5 - Coeficientes (pesos) anual e sazonal do autovetor 1 dos dados analisados.

Figure 5 -Eigen-vector 1 annual and seasonal coefficients (loadings) for the data analyzed.

Os IQAs anual, de seca e de cheia são inversamente proporcionais à qualidade desejável da água. Isso se baseia no fato de que os parâmetros utilizados, à exceção do $\mathrm{pH}$, têm padrões expressos em valores máximos permissíveis por classe de uso preponderante, nas Resoluções CONAMA 001/86 e 357/05.

No Quadro 2, mostram-se os valores de IQA para médias anual, de seca e de cheia nos pontos de captação e períodos avaliados. As maiores variações ocorreram para o IQA 1 anual e a melhor qualidade da água se refletiu no IQA 1 de seca. Os coeficientes de variação foram baixos em relação àqueles constatados por Toledo e Nicolella (2002), o que pode ser conseqüência da logaritmização dos dados, que confere certa estabilidade

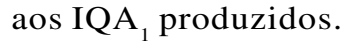

Quadro 2-IQA anual, de seca e de cheia analisados: estatística descritiva

Table 2 - Annual, drought and flood IQA, data analyzed: descriptive statistics

\begin{tabular}{lccc}
\hline Parâmetro & $\begin{array}{c}\text { IQA }_{1} \\
\text { anual }\end{array}$ & $\begin{array}{c}\text { IQA }_{1} \\
\text { seca }\end{array}$ & $\begin{array}{c}\text { IQA }_{1} \\
\text { cheia }\end{array}$ \\
\hline Valor máximo & 6,60 & 6,12 & 7,02 \\
Valor mínimo & 1,12 & 1,50 & 2,55 \\
Média & 4,92 & 4,41 & 5,27 \\
Coeficiente de variação & 0,20 & 0,18 & 0,18 \\
Range & 5,50 & 4,62 & 4,47 \\
Assimetria & $-1,04$ & $-0,73$ & $-0,42$ \\
Curtose & 2,25 & 1,42 & 0,06 \\
\hline
\end{tabular}

R. Árvore, Viçosa-MG, v.32, n.2, p.311-322, 2008
Em relação à distribuição de freqüência dos valores de IQA 1 anual, de seca e de cheia, observa-se, nesta ordem, uma progressiva tendência à normalidade (Figura 6 e Quadro 2). Quanto ao contraste sazonal, este variou entre $-38 \%$ e $+45 \%$, com um coeficiente de variação relativamente expressivo $(0,761)$, o que sugere certa inconstância na variabilidade temporal dos parâmetros.

Figura 6 - Distribuição de freqüência dos valores de IQA anual e sazonal analisados.

Figure 6-Distribution curves of annual and seasonal IQAI values analyzed.

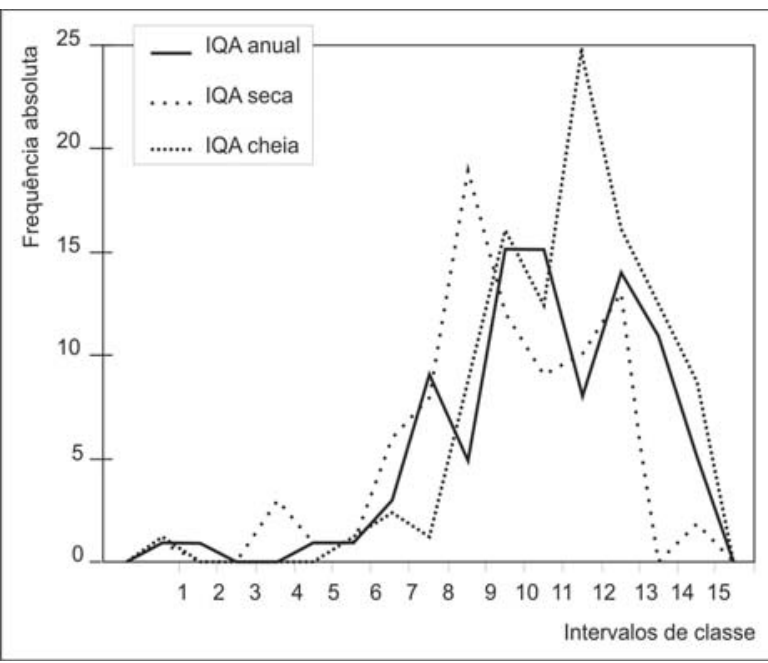




\subsection{NRVI e suas relações com o IQA}

O NRVI entre as bacias de captação avaliadas variou entre os valores extremos de -1 e +1 , com valor médio de $-0,5327$ e coeficiente de variação de 0,905 . O valor mínimo de referência de NRVI, de-0,382, é atendido por apenas $31,52 \%$ das 89 bacias de captação avaliadas, sendo que $11,95 \%$ destas se encontram integralmente convertidas (Quadro 3).

Como mostra a Figura 7, as 28 bacias que atendem ao NRVI mínimo se concentram no nordeste goiano e têm área proporcionalmente pequena, ocupando um total de 7.455.867 hectares, freqüentemente localizados em altitudes e declividades acentuadas. As 61 bacias que não atendem o NRVI mínimo, com área total de 41.050.043 hectares, predominam no centro-sul do Estado.

Quadro 3 - Distribuição de valores de NRVI nas bacias de captação analisadas

Table 3 - NRVI values distribution in the catchment area watersheds analyzed

\begin{tabular}{lc}
\hline $\begin{array}{l}\text { Valor de NRVI por } \\
\text { Bacia de Captação }\end{array}$ & $\begin{array}{c}\text { Frequiência } \\
\text { Relativa }(\%)\end{array}$ \\
\hline NRVI $=-1$ & 11,95 \\
$-0,99<$ NRVI $<-0,382$ & 56,52 \\
$-0,382<$ NRVI $<1$ & 31,52 \\
\hline Total & 100 \\
\hline
\end{tabular}

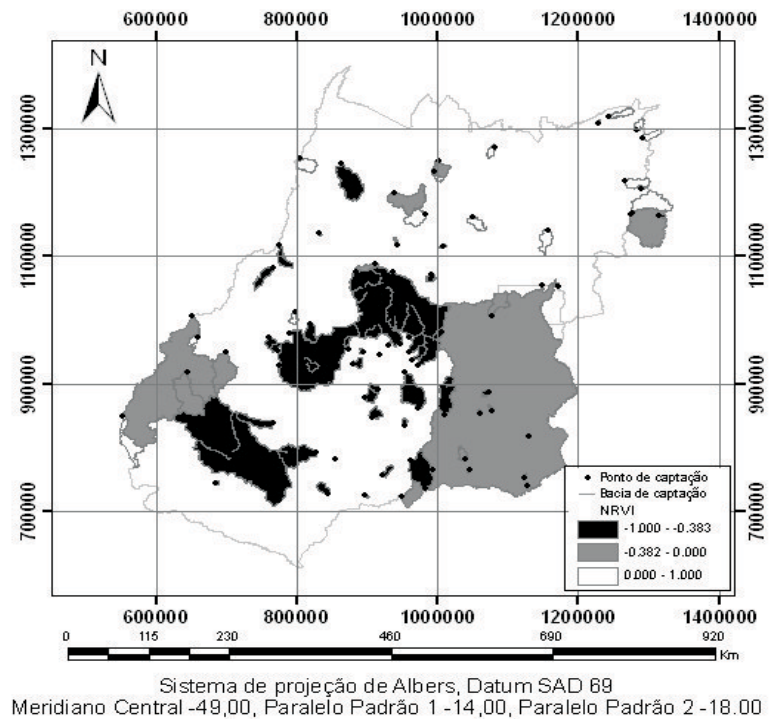

Figura 7 - Distribuição espacial dos pontos em relação às bacias de captação analisadas e respectivos valores de NRVI.

Figure 7 - Spatial distribution of catchment area points in relation to the analyzed watersheds and their respective NRVI values.
Em geral, ocupam regiões com declividade mais suave e solos de maior aptidão agrícola. Vale ressaltar que as bacias de captação com alto NRVI no nordeste se associam a alguns dos municípios com menor índice de desenvolvimento humano municipal (IDHm) em Goiás, enquanto no centro-sul ocorrem os maiores IDHm (NOVAES et al., 2006).

As Figuras 8 a 10 ilustram as relações do IQA anual, de seca e de cheia com os valores de NRVI nas bacias de captação estudadas. Os índices se relacionam por equações polinomiais quadráticas com pequenos coeficientes de determinação, sendo a dependência que melhor se caracteriza aquela entre o NRVI e o IQA anual $\left(r^{2}=0,1245\right)$.

Apesar dos baixos valores de $\mathrm{r}^{2}$, é interessante observar a tendência à concentração de valores de $\mathrm{IQA}_{1}$ mais altos nas bacias com NRVI inferior a -0,382. Isso sugere uma relação, ainda que sutil, entre uso do solo e qualidade da água para os parâmetros avaliados, com valores semelhantes de IQA anual e $_{1}$ de cheia (aproximadamente 4 a 6,5) e valores de IQA de seca um pouco menores, mas com similar amplitude (cerca de 3,5 a 6). Confirmando essa tendência, mais de $78 \%$ dos pontos de captação com valores de IQA anual e, ou, sazonal superiores a um desvio-padrão se encontram em bacias com NRVI aquém do valor mínimo de referência.

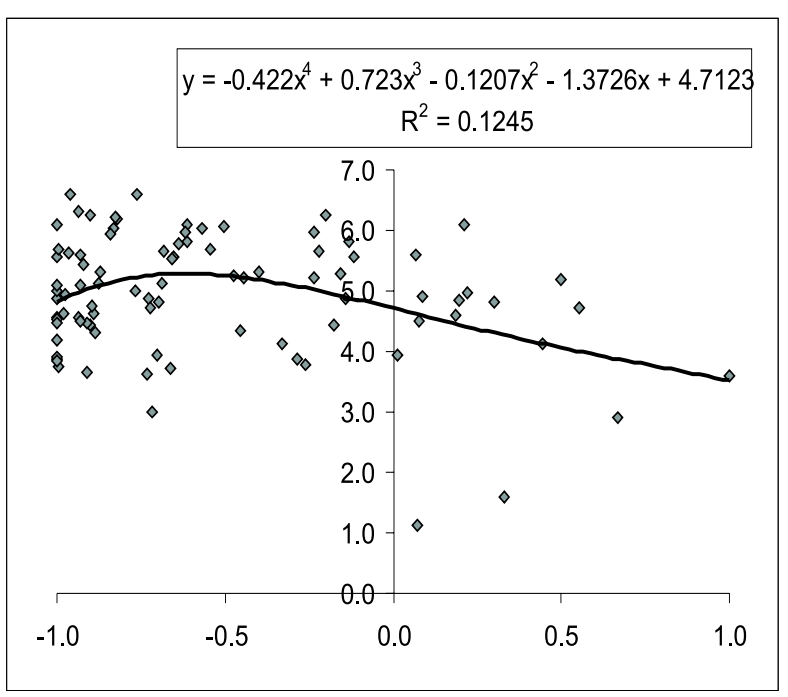

Figura 8 - Regressão entre IQA ${ }_{1}$ anual e NRVI.

Figure 8 -Regression between annual IQAI and NRVI. 


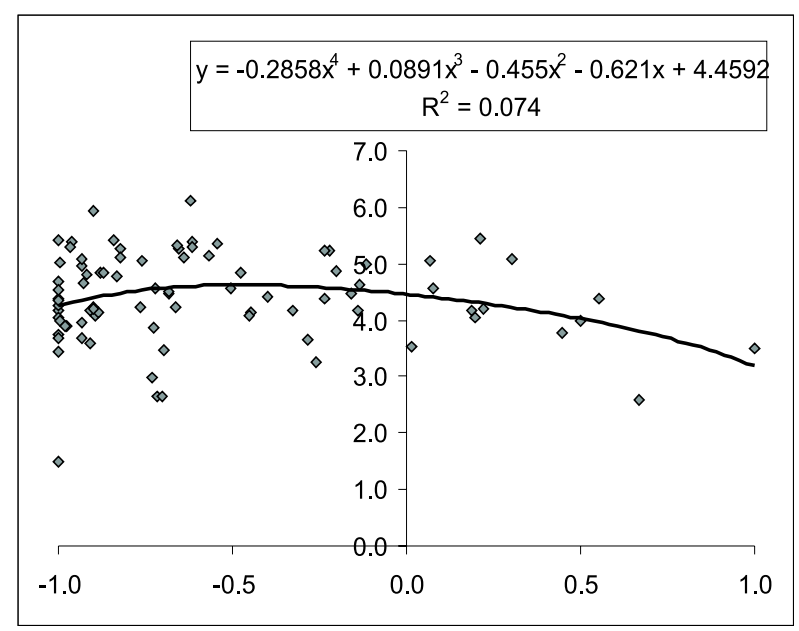

Figura 9 - Regressão entre IQA de seca e NRVI. Figure 9 -Regression between drought IQAI and NRVI.

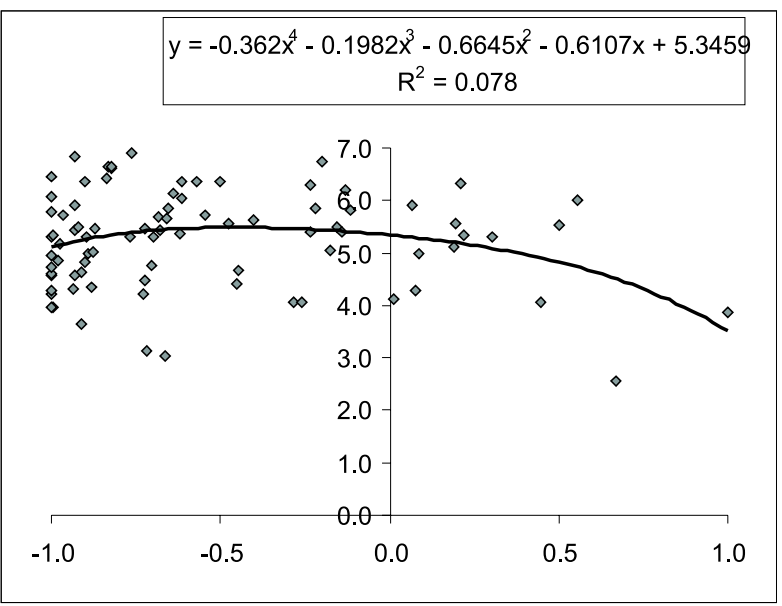

Figura 10 - Regressão entre IQA de cheia e NRVI. Figure 10-Regression between flood IQAI and NRVI.

De fato, as Figuras 8 a 10 sugerem que a variação nos valores de IQA 1 depende tanto de um controle regional (associado às amplas variações do NRVI) quanto de um componente mais localizado, restrito às áreas intensamente convertidas (valores de NRVI próximos a -1) e urbanizadas. Com vistas a discernir o efeito desses componentes, duas alternativas podem ser investigadas. A primeira é a agregação ao IQA proposto de variáveis nutricionais, como o nitrogênio e o fósforo, cujas concentrações na água são particularmente sensíveis às atividades agropastoris nas respectivas bacias (BENETTI e BIDONE, 2000;
REED e CARPENTER, 2002; RIPA et al., 2006). Da mesma forma, o uso de indicadores de uso do solo na escala paisagística de zona ripária, mais afeitos ao aporte de matéria orgânica, por exemplo, pode influenciar significativamente a relação entre IQA e NRVI (GERGEL et al., 2002; MEADOR e GOLDSTEIN, 2003; HOULAHAN e FINDLAY, 2004).

\section{CONCLUSÃO}

Os parâmetros de qualidade da água avaliados se revelam aquém dos padrões legalmente requeridos em até $62,43 \%$ dos resultados, principalmente na cheia. Parte da matéria orgânica é de origem fecal e pode ser oriunda do aporte de sedimentos, intensificado durante as chuvas associadas ao início e fim da estação chuvosa. De fato, o IQA 1 adotado apontou qualidade da água mais comprometida principalmente na cheia, como também melhor qualidade da água na seca. O uso de IQAs sazonais específicos na região favorece a precisão das inferências.

O NRVI mínimo para atender aos requisitos legais é atingido em apenas $31,52 \%$ das bacias avaliadas, concentradas no nordeste goiano. A tênue dependência do IQA 1 em relação ao NRVI deve ser mais bem investigada. Sugere-se a agregação ao IQA de variáveis nutricionais e de sólidos, ou o uso da escala de zona ripária. O entendimento sistemático e abrangente das relações entre cobertura e uso do solo e qualidade da água oportuniza uma eficaz gestão ambiental e territorial no Estado de Goiás, tendo como unidade a bacia hidrográfica e como precursor a disponibilidade quali-quantitativa da água em bacias de manancial.

\section{REFERÊNCIAS}

ANTUNES, E. C. Ativo e passivo ambiental em Goiás. In: I Workshop de Planejamento e Uso Sustentável dos Recursos Naturais do Estado de Goiás, 1., 2004, Goiânia. Anais... Goiânia: 2004. CD ROM.

AMERICAN PUBLIC HEALTH ASSOCIATION APHA. Standard methods for the examination of water and wastewater. 20.ed. Washington: APHA/AWWA/WEF, 1998.

BAKER, M. E.; WELLER, D. E.; JORDAN, T. E. Improved methods for quantifying potential nutrient interception by riparian buffers. Landscape Ecology, v.21, n.8, p.1327-1345, 2006. 
BENETTI, A.; BIDONE, F. O meio ambiente e os recursos hídricos. In. TUCCI, C. E. M. (Org.) Hidrologia: ciência e aplicação. 2.ed. Porto Alegre: UFRGS/ABRH, 2000. p.651-658.

BONNET, B. R. P.; FERREIRA, L. G.; LOBO, F. C. Sistema de Reserva Legal Extra-Propriedade no Bioma Cerrado: uma análise preliminar no contexto da bacia hidrográfica. Revista Brasileira de Cartografia, v. 58, n.2, PAGINAS, 2006

CARVALHO, A. R.; SCHLITTLER, F. H. M.; TORNISIELO, V. L. Influence of cattle ranching and agricultural activities on physical chemical parameters of water. Química Nova, v.23, n.5, p.618-622, 2000.

COMPANHIA DE TECNOLOGIA DE SANEAMENTO AMBIENTAL - CETESB. Índices de qualidade da água. Disponível em: <http://www.cetesb.sp.gov.br/ agua/rios/indice_iva_iet.asp>. Acesso em: 20 de nov. de 2006.

CONTE, M. L. et al. Qualidade da água em cachoeiras turísticas da região de Botucatu - SP: avaliação preliminar. In.: CONGRESSO INTERAMERICANO DE ENGENHARIA SANITÁRIA E AMBIENTAL, 27., 2000, Porto Alegre. Anais... Porto Alegre: ABES/AIDIS, 2000. CD ROM.

CUDE, C. G. Oregon water quality index: A tool for evaluating water quality management effectiveness. Journal of the American Water Resources Association, v.37, n.1, p.125-137, 2001.

DINIUS, S. H. Design of an index of water quality. Water Resources Bulletin, v.23, n.5, p.833-843, 1987.

FIDALGO, E. C. C. et al. Mapeamento do uso e da cobertura atual da terra para indicação de áreas disponíveis para reservas legais: estudo em nove municípios da região amazônica. Revista Árvore, v.27, n.6, p.871-877, 2003.
FREITAS, A. J. Gestão de recursos hídricos. In: SILVA, D. D. \& PRUSKI, F. F. (Eds.) Gestão de recursos hídricos: aspectos legais, econômicos, administrativos e legais. Brasília: Secretaria de Recursos Hídricos; Viçosa, MG: Universidade Federal de Viçosa; Porto Alegre: Associação Brasileira de Recursos Hídricos, 2000. 659p.

GERGEL, S. E. et al. Landscape indicators of human impacts to riverine systems. Aquatic Science, v.64, p.118-128, 2002.

\section{GIS WATER RESOURCES CONSORTIUM -} GISWR. ArcGIS Hydro Data Model. Austin: Center for Research in Water Resources, University of Texas, 2006.

HOULAHAN, J. E.; FINDLAY, C. S. Estimating the 'critical' distance at which adjacent land-use degrades wetland water and sediment quality. Landscape Ecology, v.19, p.677-690, 2004.

MEADOR, M. R.; GOLDSTEIN, R. M. Assessing water quality at large geographic scales: Relations among land use, water physicochemistry, riparian condition, and fish community structure. Environmental Management, v.31, n.4, p.504-517, 2003.

\section{MIRANDA JÚNIOR, G. X. Manejo e} preservação de recursos hídricos. Caçador: Universidade do Contestado/Pósgraduação em Gestão Ambiental, 2002. CD ROM.

NOVAES, P. C. et al. The brazilian Cerrado: A human development analysys of a hotspot biome. Earth Interactions, 2006 (submetido).

OMETO, J. P. H. B. et al. Effects of land use on water chemistry and macroinvertebrates in two streams of the Piracicaba river basin, south-east Brazil. Freshwater Biology, v.44, NUMERO, p.327-337, 2000.

ORGANIZACION MUNDIAL DE SALUD - OMS. Guías para la calidad del água potable. 2.ed. Genebra: 1995. 195p.

R. Árvore, Viçosa-MG, v.32, n.2, p.311-322, 2008 
PIMENTEl, M. F. Análise estatística de dados do monitoramento da qualidade das águas do rio Ipojuca e do reservatório Tapacurá: Relatório Final Consolidado. Programa Nacional do Meio Ambiente II - PNMA II, Projeto: Monitoramento da Qualidade da Água como Instrumento de Controle Ambiental e Gestão de Recursos Hídricos no Estado de Pernambuco. Recife: 2003. 80p.

REED, T.; CARPENTER, S. R. Comparisons of P-yield, riparian buffer strips, and land cover in six agricultural watersheds. Ecosystems, v.5, n.6, p.568-577, 2002.

RIBEIRO, C. A. A. S. et al. O desafio da delimitação de áreas de preservação permanente. Revista Árvore, v.29, n.2, p.203-212, 2005.

RIPA, M. N. et al. Agricultural land use and best management practices to control nonpoint water pollution. Environmental Management, 2006. Published on-line: 15 June 2006.

SANO, E. E. et al. Padrões de cobertura de solos do Estado de Goiás. In.: FERREIRA, L. G. (Org.)

Conservação da biodiversidade e sustentabilidade ambiental em Goiás: prioridades, estratégias e perspectivas. Goiânia: SEMARH/AGMA/World Bank, 2006. p. 76-93.

SANTOS, R. F. Planejamento ambiental: teoria e prática. São Paulo: Oficina de Textos, 2004. 184p.

SNYDER, M. N.; GOETZ, S. J.; WRIGHT, R. K. Stream health rankings predicted by satellite derived land cover metrics: Impervious area, forest buffers and landscape configuration. Journal of the American Resources Association, v.41, n.3, p.659-677, 2005.
SPERLING, M. Introdução à qualidade de águas e ao tratamento de esgotos. 2.ed. Belo Horizonte: DESA/UFMG, 1996. 243p.

TOLEDO, L.G.; NICOLELLA, G. Índice de qualidade de água em microbacia sob uso agrícola e urbano. Scientia Agricola, v.59, n.1, p.181186, 2002.

TUCCI, C. E. M. Controle de enchentes. In. TUCCI, C. E. M. (Org.) Hidrologia: ciência e aplicação. 2.ed. Porto Alegre: UFRGS/ABRH, 2000. p.651-658.

\begin{tabular}{ll} 
Anexo 1 - Lista de Siglas \\
\hline Sigla & \multicolumn{1}{c}{ Nome } \\
\hline SANEAGO & Saneamento de Goiás S/A \\
IQA & Índice de Qualidade da Água \\
SRTM & Shuttle Radar Topography Mission \\
NRVI & Índice Normalizado de Vegetação Remanescente \\
ICT & Índice de Coliforme Total \\
ICF & Índice de Coliforme Fecal \\
NTU & Unidade de Turbidez Nefelométrica \\
NMP & Número mais Provável \\
CONAMA & Conselho Nacional de Meio Ambiente \\
CETESB & Companhia de Tecnologia de SaneamentoAmbiental \\
OD & Oxigênio Dissolvido \\
DBO & Demanda Bioquímica de Oxigênio \\
IAP & Índice de Qualidade da Água para Abastecimento \\
& Público \\
IVA & Índice de Qualidade da Água para Proteção da \\
& Vida Aquática \\
OWQI & Oregon Water Quality Index \\
LUI & Land Use Index \\
NRVI & Normalized Remaining Vegetation Index \\
UH & Unidade Hazen de Cor \\
MDT & Modelo Digital do Terreno \\
IDHm & Índice de Desenvolvimento Humano Municipal \\
\hline &
\end{tabular}

